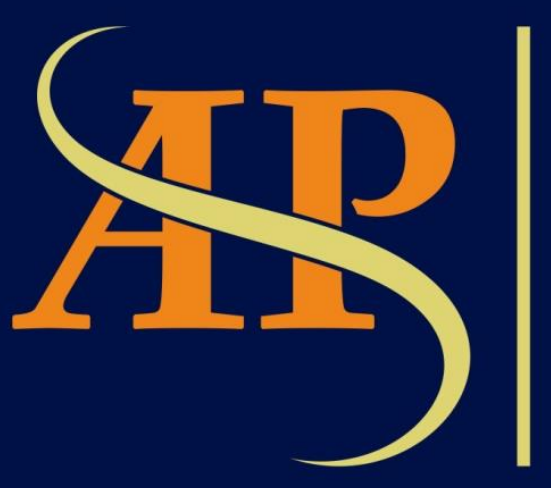

JURNAL

ASIA

PACIFIC

STUDIES

Journal of International Relations Study Program Faculty of Social and Political Sciences

Universitas Kristen Indonesia

Volume 3 | Number 2 | July - December 2019 


\title{
KEPENTINGAN INDONESIA DALAM MENGAMBIL ALIH FLIGHT INFORMATION REGION(FIR) DARI SINGAPURA
}

\author{
Alwafi Ridho Subarkah \\ Pascasarjana Hubungan Internasional, Fakultas Ilmu Sosial dan Ilmu Politik \\ Universitas Padjadjaran, Bandung \\ alwafisubarkah@gmail.com
}

\begin{abstract}
Each state should maintain their sovereignty as a whole, especially on their territory which includes air, land and sea. However, Indonesia has not been fully sovereign in its airspace. For instance, Air Traffic Control (ATC) is still controlling flight identification zones in Western Indonesia, such as Serawak, Tanjung Pinang, Malacca Peninsula, Natuna and Riau Islands. This was a threat because when the Indonesian Armed Forces aircraft on patrol and training had to report to the Singapore ATC, economically it also required Indonesia to pay fees to Singapore if it passed through the area.This research aims to shows the Indonesian interest in taking over the Flight Information Region (FIR) in a bid to safeguard the sovereignty of Indonesia. The method in this research is qualitative method that describes and explains research problems related to the topics discussed and triangulates methods and data. This research uses the concept of national interest, where the state has ability to protect and defend its national interests sovereignly by making various policies. The results of this research show that the interest of Indonesia is to fully maintain their sovereignty by making Law No. 1 of 2009 concerning about Aviation and Government Regulation No. 4 of 2018 concerning Security of the Republic of Indonesia Airspace, improving human resources and technology. On an international scale, efforts continue to be made through the International Civil Aviation Organization (ICAO) so that the FIR managed by the Singapore ATC can be managed by Indonesia. Thus, any diplomatic and foreign aircraft security clearance processed through the Indonesian government.
\end{abstract}

Keywords: National Interest, Sovereignty, Air Sovereignty, Territory Control

\begin{abstract}
Abstrak
Kedaulatan setiap negara harus dijaga secara keseluruhan, pada konteks ini adalah kedaulatan wilayah yang mencakup udara, darat dan laut. Namun Indonesia belum berdaulat dalam udara sepenuhnya. Bagian barat Indonesia, seperti Serawak, Tanjung Pinang, Semenanjung Malaka, Natuna dan Kepulauan Riau dalam mengelola zona identifikasi penerbangan dikuasai oleh Air Traffic Control (ATC) Singapura. Hal ini menjadi ancaman karena saat pesawat Tentara Nasional Indonesia dalam patroli maupun latihan melapor ke Singapura, secara ekonomi juga mengharuskan Indonesia untuk membayar biaya kepada Singapura jika melewati wilayah tersebut. Tujuan penelitian yaitu menunjukkan kepentingan Indonesia dalam mengambil alih Flight Information Region (FIR) sebagai upaya untuk menjaga kedaulatan Indonesia. Metode dalam penelitian ini yaitu metode kualitatif yang mendeskripsikan dan menjelaskan permasalahan penelitian terkait topik yang dibahas dan melakukan triangulasi metode dan data. Penelitian ini menggunakan konsep national interest yaitu kemampuan negara dalam melindungi maupun mempertahankan kepentingan nasionalnya secara berdaulat dengan mengeluarkan berbagai kebijakan. Hasil penelitian ini, kepentingan Indonesia adalah menjaga kedaulatan sepenuhnya dengan membuat Undang-Undang No. 1 Tahun 2009 tentang Penerbangan serta Peraturan Pemerintah No. 4 Tahun 2018 tentang Pengamanan Wilayah Udara Republik Indonesia, meningkatkan sumber daya manusia dan meningkatkan teknologi. Pada skala internasional terus dilakukan upaya melalui International Civil Aviation Organization (ICAO) agar FIR yang dikelola oleh ATC Singapura dapat dikelola oleh Indonesia sehingga izin diplomatik dan izin keamanan pesawat asing melalui pemerintah Indonesia.
\end{abstract}

Kata Kunci: Kepentingan Nasional, Kedaulatan, Kedaulatan Udara, Pengelolaan Wilayah 


\section{Pendahuluan}

Kedaulatan harus dijaga secara utuh oleh negara, baik secara politik, ekonomi, hingga wilayah yang mencakup perairan, daratan, hingga ruang udara, tanpa adanya intervensi dari negara lain. Berdasarkan Perjanjian Perdamaian Westphalia yang ditandatangani pada tahun 1948 menyatakan dalam prinsip hukum internasional bahwa negara memiliki kedaulatan atas wilayah dan urusan domestiknya, mengesampingkan kekuatan eksternal, dengan prinsip tidak ada campur tangan negara lain, dan setiap negara setara di hadapan hukum internasional.

Alaein de Benoist menyatakan bahwa kedaulatan merupakan bentuk negara yang merdeka, tidak ada campur tangan negara lain dalam mengelola urusan dalam negeri negara tersebut. Kedaulatan negara tidak hanya bergantung pada negara itu sendiri, tetapi juga dilihat kedudukannya saat berhadapan dengan negara berdaulat lainnya. (Kostova, J, 2015). Sehingga kedaulatan negara bergantung pada negara satu dengan lainnya sebagai negara merdeka.

Viktor Koščo berpendapat ada dua dimensi kedaulatan, yaitu: internal dan eksternal. Internal terdiri dari hak kedaulatan negara dalam pengambilan keputusan dan otoritas penegakan hukum di wilayah tertentu yang dihuni oleh populasi tertentu. Sedangkan dimensi eksternal adalah pengakuan dari negara lain. (Viktor Koščo, 2016:29).

Königová mengatakan bahwa ada dua unsur penting kedaulatan, yaitu: Pertama, universalitas yaitu kemampuan untuk menundukkan semua entitas di wilayah tertentu, terlepas dari cara pengelompokannya. Kedua, penciptaan hukum yang ditandai oleh fakta bahwa semua bidang kegiatan diatur oleh standar hukum yang diakui oleh otoritas negara. (Königová, 2001:42). Negara kedaulatan yaitu negara memiliki kewenangan tertinggi dalam menjalankan pemerintahannya sesuai dengan hukum yang berlaku.

Kedaulatan menurut David A. Lake berhubungan dengan kewenangan, adapun kewenangan ini memiliki tiga karakteristik, yaitu: pertama, kekuasaan merupakan hal yang mendasar dari kewenangan, dapat dilakukan dengan sukarela maupun tidak. Kedua, kewenangan itu bersifat unik, ada hak ilahi, tradisi, dukungan rakyat, dan sebagainya. Ketiga, kewenangan tidak bersifat absolut. Kedaulatan terdiri dari kewenangan internal dan eksternal, internal yaitu kedaulatan pada zaman dahulu dipegang oleh raja, sekarang dapat berupa kepala pemerintahan, juga dapat kedaulatan rakyat atau orang. Sedangkan eksternal maksudnya pengakuan dari negara lain. (David A. Lake, 2003:304-305).

Hans J. Morgenthau kedaulatan itu sama halnya dengan independence yaitu negara memiliki kewenangan sendiri mengatur kedaulatan sendiri, lalu equality bahwa negara satu dengan yang lainnya tidak ada yang lebih tinggi atau rendah kedudukannya sebagai negara merdeka, dan yang terakhir unanimity yaitu konsensus antara negara berdaulat harus diterima oleh semua pihak. (Hans J. Morgenthau, 1948:345-347).

Menurut Janice E. Thomson Kedaulatan adalah pengakuan oleh aktor internal dan eksternal bahwa negara memiliki wewenang eksklusif untuk campur tangan secara paksa dalam kegiatan di dalam wilayahnya. Elemen kunci dalam definisi ini adalah pengakuan, negara, otoritas, paksaan, dan wilayah (Janice E. Thomson, 1995: 219).

Jadi dapat disimpulkan bahwa kedaulatan merupakan upaya negara mengelola wilayahnya sesuai dengan ketentuan yang ada dalam negara itu sendiri tanpa adanya campur tangan dari negara lain, serta setiap negara yang berdaulat memiliki kesetaraan dengan negara lain, dan negara yang berdaulat memerlukan pengakuan dari negara lain.

Kedaulatan negara terkait dengan wilayah, negara biasanya terdiri dari tiga dimensi yaitu udara, darat, dan laut. Namun, tidak semua negara memiliki tiga dimensi tersebut, ada istilah dalam hukum internasional yaitu landlocked states, negara yang hanya memiliki dua dimensi (udara dan darat) seperti Nepal, Laos, Kamboja, Austria, Congo, Irak, Swiss, Nigeria, Kazakhstan, dan lainnya. Negara yang terdiri dari tiga dimensi seperti Indonesia, Malaysia, 
Singapura, India, Filipina, Inggris, Pakistan, Jepang, Korea, China, dan lainnya. (Baiq Setiani, 2017:491). Dapat dilihat bahwa setiap negara memiliki pasti memiliki wilayah udara dan ini juga menjadi sangat penting.

Indonesia sebagai negara memiliki wilayah yang luas belum mampu sepenuhnya mengelola wilayahnya, terutama ruang udara di wilayah Batam dan Natuna dikuasai oleh Singapura dan Malaysia. Berdasarkan hasil pertemuan International Civil Aviation Organization (ICAO) pada Maret 1964 di Dublin, Irlandia, menyatakan Flight Information Region (FIR) wilayah udara Indonesia 100 mil laut atau 1.825 kilometer dikuasai negara lain. FIR wilayah udara yang dikuasai mencakup blok A, blok B, dan Blok C. Blok A mencakup di atas 8 kilometer sepanjang Batam dan Singapura; blok B mencakup Tanjung Pinang dan Karimun; dan blok C mencakup wilayah udara Natuna dikuasai oleh Singapura di atas 24.500 kaki, dan Malaysia di bawah 24.500 kaki. (CNN Indonesia, 2018). Sebagai negara berdaulat, Indonesia tentu dirugikan karena mengharuskan penerbangan sipil maupun militer di wilayah udara Indonesia melapor ke FIR Singapura atau Malaysia meskipun berada wilayah Indonesia, misalnya penerbangan dari Natuna ke Tanjung Pinang harus melapor terlebih dahulu ke FIR Singapura.

Selain dilihat dari segi kedaulatan, wilayah Indonesia yang dikuasai oleh FIR Singapura tersebut dapat dilihat dari segi ekonomi. Penerimaan dari aktivitas penerbangan di wilayah penguasaan FIR Singapura bagi Indonesia hanya mendapatkan sharing. Sedangkan pergerakan penerbangan setiap hari di wilayah tersebut mencapai 10.000. (CNN Indonesia, 2018). Dapat dipastikan negara lain mengambil keuntungan dengan ikut campur dalam mengelola wilayah tertentu, dalam hal ini adalah Singapura yang mengelola Batam, Natuna, dan wilayah sekitarnya.

Pengelolaan wilayah udara yang dikuasai oleh Singapura dari hasil pertemuan ICAO pada tahun 1964 tersebut menilai bahwa saat itu Indonesia belum mampu mengelola wilayah udara sekitar itu karena belum memenuhi infrastruktur, misalnya pada tahun 1964 Indonesia belum memiliki bandara terdekat di wilayah udara itu. Sehingga, atas dasar keselamatan penerbangan internasional, negara terdekat yang dianggap mampu saat itu adalah Singapura dan berhak meminta pembayaran dari aktifitas penerbangan dari seluruh maskapai di area tersebut, pada saat bersamaan Singapura sedang dijajah oleh Inggris yang membantu lobby dan mempersiapkan infrastruktur penerbangan. Maka dari itu, Indonesia sangat perlu untuk mengambil alih FIR yang dikuasai Singapura di wilayah udara tersebut, misalnya pembaruan perjanjian tahun 1964 beberapa kali hingga akhirnya Indonesia dan Singapura bersepakat bahwa Singapura akan mengembalikan FIR wilayah udara di Batam dan Kepulauan Riau dikembalikan dalam jangka 15 tahun sejak peraturan perundangan ditetapkan, sesuai dengan Undang-Undang No. 1 Tahun 2009 Tentang Penerbangan. (Elza Astari Retaduari, 2015).

Alasan kedaulatan yang dapat mengancam keamanan nasional Indonesia karena Singapura dapat mengetahui kegiatan penerbangan sipil dalam negeri, bahkan penerbangan militer Indonesia, juga potensi penerimaan ekonomi kegiatan penerbangan di wilayah tersebut menjadi latar belakang penelitian ini untuk mengetahui lebih lanjut bagaimana upaya dan kepentingan nasional Indonesia dalam mengambil alih FIR dari Singapura.

Pengelolaan FIR di wilayah udara Indonesia oleh Singapura menjadi permasalahan penelitian ini, karena ini menyangkut kedaulatan negara dan juga segi keuntungan ekonomi. Sehingga Penelitian ini bertujuan untuk mengetahui upaya Indonesia dalam mengambil alih Flight Information Region yang dikuasai oleh Singapura dan kepentingan Indonesia dalam mengambil alih hal tersebut sebagai upaya dalam mengelola kedaulatan Indonesia terhadap wilayahnya di ruang udara. 


\section{Metode Penelitian}

Dalam penelitian ini menggunakan metode penelitian kualitatif menjelaskan dan mendeskripsikan permasalahan dalam hal ini adalah upaya pengambil alihan FIR Indonesia dari Singapura dan kepentingan Indonesia dalam mengambil alih FIR tersebut. Penelitian ini disajikan berupa gambar, tabel, grafik, diagram, juga narasi sebagai upaya menjawab rumusan masalah. Teknik pengumpulan data dilakukan dengan studi pustaka. Adapun teknik analisis data dilakukan dengan reduksi data memilah data yang dianggap relevan dengan penelitian ini, kemudian dilakukan penyajian data yaitu menampilkan narasi, gambar, grafik, tabel, dan terakhir menarik kesimpulan.

\section{Landasan Teori}

Pada penelitian ini menggunakan konsep kepentingan nasional. Setiap negara memiliki kepentingan masing-masing sesuai dari kebutuhan dari negara itu sendiri untuk memenuhi masyarakat yang ada di wilayah negara tersebut. Thomas Hobbes memandang bahwa negara memiliki tanggung jawab dalam melindungi masyarkat, cara hidup masyarakatnya, dan juga wilayahnya. (Jackson dan Sorensen, 2009: 89). Kepentingan nasional berarti kemampuan negara melindungi wilayahnya dan kebutuhan masyarakatnya.

Sedangkan Han J. Morgenthau menganggap kepentingan nasional setiap negara berbeda karena tradisi dan kultur politik luar negerinya sesuai dengan kebutuhan negara tersebut. (P.Anthonius Sitepu, 2011: 163). Tradisi dimaksudkan sistem pemerintahan atau atribut negaranya, sedangkan kultur politik berupa kebiasaan masyarakatnya yang dapat mencerminkan politik luar negeri negara tersebut. Sehingga dua hal ini menjadi penting setiap negara dalam mengambil keputusan untuk membuat kebijakan luar negeri sebagai upaya mencapai kepentingan nasional.

Morgenthau melanjutkan bahwa kepentingan nasional setiap negara pada akhirnya bertujuan untuk mencapai kekuasaan, dalam artian negara ingin terlepas dari campur tangan negara lain yang dapat diwujudkan dengan teknik paksaan atau kerja sama. Menurutnya, dua hal yang menjadi kunci dari kepentingan nasional, yakni power (kekuasaan) dan keinginan. (Hans J. Morgenthau, 1951). Gagasan kepentingan nasional menurut Morgenthau juga pada umumnya menyerupai konstitusi Amerika Serikat dalam dua hal, seperti kesejahteraan umum dan klausul proses hukum. (Hans J. Morgenthau, 1949). Menganggap bahwa dua faktor yang sangat mempengaruhi kepentingan nasional, yaitu rasionalitas dan situasi. (Hans J. Morgenthau, 1950)

Kepentingan nasional juga bersifat dua hal, yaitu vital dimana kepentingan ini bersifat penting atau genting yang sangat perlu diputuskan saat itu; kedua adalah non-vital kepentingan yang bersifat dampaknya tidak secara langsung dirasakan atau kepentingan yang sifatnya jangka panjang. (Aleksius Jemadu, 2008: 67-69). Dalam pengertian lain kepentingan nasional yang pertama berupaya agar segera dilaksanakan, sedangkan yang kedua bersifat jangka panjang.

Sehingga kita mendapat pengertian bahwa kepentingan nasional yaitu merupakan instrumen negara untuk mencapai keinginannya. Dalam mencapai kepentingan tersebut harus melihat berbagai hal baik dari dalam negeri maupun luar negeri, hal ini bertujuan untuk mengukur kemampuan negara dalam mengeluarkan kebijakan agar keinginannya tercapai. Selain kemampuan negara yang juga menjadi penting adalah melihat kepentingan nasional tersebut bersifat vital atau tidak, ini dilakukan agar negara memiliki kalkulasi keinginan yang harus dicapai dalam waktu dekat dan jangka panjang. 
Pada konteks penelitian ini, peneliti ingin melihat kepentingan nasional Indonesia dalam mengambil alih FIR dari Singapura yang sifatnya vital sebagai upaya untuk melindungi kedaulatan negara di ruang udara dan bebas dari campur tangan negara lain dalam mengelola wilayah udaranya, karena wilayah udara merupakan area yang strategis.

\section{Pembahasan}

Wilayah udara Indonesia tidak sepenuhnya berdaulat. Hal ini terlihat adanya campur tangan negara lain mengelola wilayah tertentu meski secara geografis itu adalah bagian dari wilayah Indonesia. Sehingga penerbangan sipil maupun militer yang dilakukan harus melakukan izin clearance dari negara lain, izin dari negara lain ini tentu cukup mengganggu karena penerbangan militer pun harus izin terlebih dahulu jika melakukan kegiatan latihan atau sebagainya padahal wilayah tersebut masih termasuk bagian dari Indonesia

Istilah Flight Information Regions yang dikuasai oleh Singapura memiliki pengertian bahwa wilayah udara yang terdiri dari informasi penerbangan dan informasi layanan kesiagaan. Pengertian FIR tersebut sesuai dengan Annex 11 to the Convention on International Civil Aviation yang memuat Air Traffic Services terdiri dari Air Traffic Control Services, Flight Information Services, dan Alerting Services. Sedangkan FIR ini merupakan bagian upaya pelayanan penerbangan mengandung pengertian: "Flight Information Regions: Those portions of the airspace where it is determined that flight information service and alerting service will be provided shall be designated as flight information regions." (International Civil Aviation Organization, 2001). FIR dibentuk pada sembilan wilayah, dan salah satunya adalah FIR Natuna yang kemudian menjadi bagian Flight Information Regions Over the South China Sea Oceanic Airspace yang dikenal saat ini menjadi Singapore Flight Information Region. (Evi Zuarida, 2012: 34). FIR Singapura ini meliputi wilayah Indonesia, diantaranya Kepulauan Riau

Kepulauan Riau secara geografis merupakan daerah terluar dari Indonesia yang berbatasan langsung dengan Provinsi Riau, negara Singapura dan Malaysia di Sebelah Barat. Sebelah Timur berbatasan dengan Kalimantan Barat dan Malaysia. Sebelah Selatan berbatasan dengan Provinsi Jambi dan Provinsi Sumatera Selatan. Sedangkan Sebelah Utara berbatasan langsung dengan Laut Cina Selatan di sana terdapat Pulau Senau yang menjorok memisahkan antara Malaysia Barat dan Timur, wilayah tersebut dikelola oleh FIR Singapura. (Muhammad Ridwan Saptian, 2017: 114).

Pengelolaan FIR Singapura ini sesuai dengan Annex 11 tentang layanan lalu lintas penerbangan pada bagian 2.1.1 (ICAO, 2001):

Contracting States shall determine, in accordance with the provisions of this Annex and for the territories over which they have jurisdiction, those portions of the airspace and those aerodomes where air traffic services will be provided. They shall thereafter arrange for such services to be established and provided in accordance with the provisions of this Annex, except that, by mutual agreement, a State may delegate to another State the responsibility for establishing and providing air traffic services in flight information regions, control areas or control zones extending over the territories of the former.

Dengan adanya aturan tersebut memungkinkan kedua negara yakni Indonesia dan Singapura melakukan kesepakatan dalam mengelola wilayah udara pada area tersebut. Indonesia mendelegasikan wilayah udara Kepulauan Riau yang berbatasan langsung dengan Laut Cina Selatan tersebut ke FIR Singapura. 


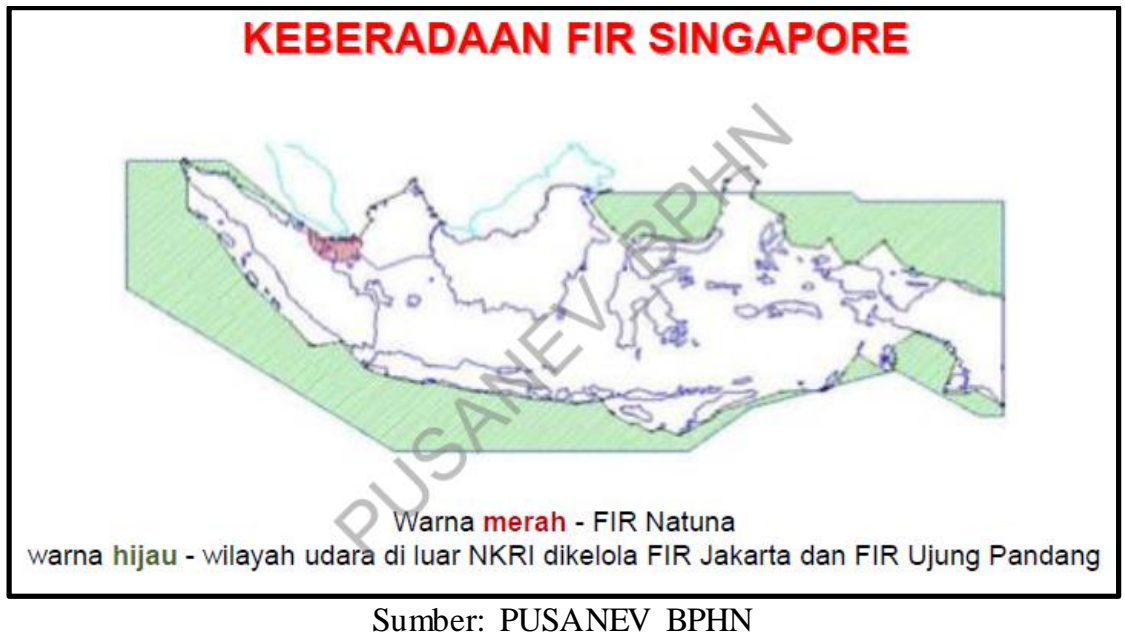

Singapura mengelola wilayah udara Indonesia sekitar 100 mil laut atau sekitar 1.825 kilo meter yang meliputi Semenanjung Malaka, Kepulauan Riau, Serawak, Natuna, Tanjung Pinang. Upaya mengambil alih FIR Singapura telah dilakukan oleh Indonesia sejak tahun 1991 dengan mengajukan pengambil alihan FIR tersebut ke Indonesia, namun perlu adanya persetujuan dari ICAO. Pada tahun 1993 Indonesia kembali mengajukan pengambil alihan FIR dalam pertemuan Navigasi Udara Regional di Bangkok yang diselenggarakan oleh ICAO, namun mengalami kegagalan karena Indonesia kalah lobi yang mengirimkan delegasi Pejabat Eselon I, sedangkan Singapura mengirimkan delegasi menteri terkait. Lalu pada Januari 2012 dilakukan pertemuan antara Singapura dan Indonesia di Bali yang menghasilkan agar pengembalian FIR yang mengelola sektor A wilayah udara mencakup Natuna dan Batam akan dikembalikan ke Indonesia. (Kumparan.com, 2018)

Hasil Laporan Kunjungan Kerja Panitia Kerja Komisi V Dewan Perwakilan Rakyat Republik Indonesia ke Bandara Hang Nadim Batam Provinsi Kepulauan Riau pada 1-2 April 2015 menemukan adanya koordinasi navigasi atau lalu lintas penerbangan antara Indonesia dan Singapura di wilayah Kepulauan Riau dan Natuna dikelola oleh FIR Singapura sejak 1995 dan Singapura akan mengembalikan pengelolaan FIR Singapura ke Indonesia yang memerlukan persetujuan ICAO, juga terjadi kendala secara politis karena Malaysia menjadi Dewan ICAO dan Indonesia anggota biasa. Sehingga DPRI RI mendesak pemerintah mengambil alih FIR Singapura sesuai dengan Undang-Undang No. 1 Tahun 2009 Tentang Penerbangan pada Pasal 458 "Wilayah udara Republik Indonesia, yang pelayanan navigasi penerbangannya didelegasikan kepada negara lain berdasarkan perjanjian sudah harus dievaluasi dan dilayani oleh lembaga penyelenggara pelayanan navigasi penerbangan paling lambat 15 (lima belas) tahun sejak UndangUndang ini berlaku". Harus melibatkan Menko Politik Hukam dan HAM, Menteri Luar Negeri, Menteri Perhubungan dan Menteri/Lembaga terkait lain. Sehingga pengembalian FIR Singapura ke Indonesia paling cepat tahun 2019 dan paling lambat tahun 2024 (DPR RI, 2015).

Berberapa alasan yang mengharuskan FIR Singapura harus diambil alih oleh Indonesia, yakni (Koesnadi Kardi, 2016): Alasan mengambil alih FIR Singapura ini sesuai dengan landasan hukum yang berlaku di Indonesia, yakni pembukaan Undang-Undang Dasar 1945 pada alenia keempat yang berbunyi: “...Kemudian dari pada itu untuk membentuk suatu 
Pemerintahan Negara Indonesia yang melindungi segenap bangsa Indonesia dan seluruh tumpah darah Indonesia dan untuk memajukan kesejahteraan umum..." pada frasa melindungi segenap bangsa dan seluruh tumpah darah Indonesia ini mencakup wilayah udara, laut maupun darat harus dapat dilindungi oleh negara karena sejak 1946 Singapura mengelola wilayah udara tersebut.

Alasan lain data intelijen dapat dengan mudah diperoleh oleh Singapura secara detail di Kepulauan Riau dan Natuna; air power Indonesia harus mampu melindungi seluruh wilayah udara untuk mendukung upaya mencapai poros maritim dunia; pengambilan FIR dari Singapura ini sesuai dengan amanat UU No. 1 Tahun 2019 tentang Penerbangan.

Upaya pengambilalihan ini tentunya harus diikuti oleh Sumber Daya Manusia yang mampu menguasai pengaturan lalu lintas penerbangan sesuai standar ICAO yang harus dipenuhi. Selain itu juga penerbang Indonesia yang masih kurang, karena orang asing yang lebih banyak bekerja di industri penerbangan nasional.

Koesnadi Kardi memberikan solusi upaya yang harus dilakukan oleh Indonesia adalah membuat batas wilayah udara; memperbaiki kualitas penerbangan sesuai standar ICAO; harus mampu memiliki pesawat "air surveillance" atau "maritime air surveillance" untuk mendapatkan data intelijen yang akurat dan mencegah illegal fishing; menyediakan software dan hardware untuk menunjang kemampuan Management Air Traffi; mengalokasikan anggaran APBN yang cukup untuk menunjang terwujudnya road-map pengambil alihan FIR Singapura; wakil Indonesia harus memiliki kemampuan berdiplomasi dan memiliki pemahaman yang baik tentang air safety dan air power wilayah NKRI sebagai upaya diplomasi di tingkat internasional dalam memperjuangkan posisi Indonesia di ICAO. (Koesnadi Kardi, 2016).

\subsection{Kesepakatan Indonesia dan Singapura dalam Pengelolaan Singapura}

Negosiasi antara Singapura dan Indonesia mulai menemukan titik kesepakatan. Hal ini terlihat saat Presiden Joko Widodo selaku Presiden Indonesia saat berkunjung ke Singapura dan bertemu dengan Perdana Menteri Singapura Lee Hsien Loong pada 8 Oktober 2019 masing-masing Kepala Negara memberikan Joint Press Statement bahwa dalam hal Flight Information Region sepakat untuk melakukan negosiasi ke tahap teknis. (Seskab RI, 2019). Presiden RI Joko Widodo menyatakan:

"Indonesia also welcomes the framework for negotiation of FIR Realignment agreed by the two countries. Indonesia respects the position of Singapore which understands Indonesia's wish to oversee its own airspace. Our technical team have started negotiation. We encourage the negotiation to speedily achieve concrete result." (Seskab RI, 2019)

Perdana Menteri Singapura Lee Hsien Loong menyatakan:

"Two such issues are airspace management, specifically the status of the Flight Information Region (FIR), and secondly military training in accordance with the United Nations Convention on the Law of the Sea, or UNCLOS. Over the last few months, our Ministers and officials have held preliminary discussion on these issues. They have agreed on a framework for discussion, laying out the core principles and considerations concerning these issues. This framework acknowledges that the core interests and rights of both countries must be recognised and respected, and that Indonesia and Singapore should negotiate agreements on these two issues that are durable and for the long haul. The framework offers a 
sound and comprehensive basis to work out solutions to these two issues, separately but concurrently.

President Jokowi and I are happy at this progress. We have instructed our Ministers and officials to follow up with detailed negotiations on the basis of this framework, and to conclude and implement the agreements in a timely manner." (Prime Minister's Officer Singapore, 2019)

Kepala negara tersebut menyatakan kesepakatan dan melakukan penandatanganan kerjasama sehingga selanjutnya pada tahap teknis sesuai dengan peraturan dari ICAO. Maka dari itu yang harus dilakukan oleh Indonesia adalah mempersiapkan sumber daya manusia yang mampu mengoperasikan FIR tersebut, dan tentunya teknologi yang mumpuni dalam mendukung keamanan penerbangan di daerah Kepulauan Riau dan sekitarnya sesuai standarisasi ICAO, karena belajar dari sebelumnya bahwa Singapura diberikan kewenangan mengendalikan wilayah tersebut pada saat itu memang siap dan mampu. Namun, saat ini pihak Singapura sudah mempercayai bahwa Indonesia sudah siap untuk mengelola FIR tersebut.

\subsection{Kepentingan Indonesia dalam Mengambil Alih FIR}

Berdasarkan fakta dan data yang ditunjukkan bahwa kedaulatan negara terlihat terancam karena wilayah udara negara lain dikuasai oleh negara lain. Sesuai dengan pengertian kedaulatan negara yaitu negara memiliki kemampuan untuk mengelola seluruh wilayahnya baik dimensi darat, laut, maupun udara.

Wilayah udara merupakan area yang sangat strategis dan memiliki nilai ekonomis, dibuatlah perjanjian atar negara untuk saling membatasi wilayah yang menjadi otoritasnya, maka dibuatlah perjanjian tentang kedaulatan udara dalam konvensi Chicago 1944.

Pada penelitian ini melihat kepentingan nasional Indonesia dalam mengambil alih dari FIR Singapura ini karena letak strategis dan jumlah penerbangan tinggi di daerah yang menjadi wilayah udara FIR itu. Sesuai dengan atribut nasional Indonesia seperti UndangUndang yang mengatur penerbangan, memaksa pemerintah untuk segera mengambil alih FIR Singapura, karena kepentingan nasional menguasai wilayah udara di Kepulauan Riau dan Natuna itu bersifat vital yang harus segera diambil alih, dikarenakan penguasaan oleh Singapura sudah berlangsung lama.

Jika wilayah udara dikuasai oleh Indonesia di wilayah tersebut akan leluasa dalam melakukan penerbangan di area Kepulauan Riau, Natuna dan sekitarnya tanpa harus melakukan permohonan izin ke Singapura, penerbangan militer pun juga menjadi leluasa, dan Indonesia dapat menerima pendapatan dari izin penerbangan yang melintasi wilayah tersebut.

Alasan utama Indonesia mengambil alih FIR Singapura sesuai dengan kepentingan nasional adalah alasan keamanan nasional. Untuk mencapai kepentingan tersebut, Indonesia harus memiliki Sumber Daya Manusia yang mumpuni dalam mengelola lalu lintas penerbangan, memiliki SDM yang mampu bekerja di Industri penerbangan secara kualitas dan kuantitas, dan juga Indonesia harus mampu memiliki infrastruktur baik teknologi yang mumpuni sesuai dengan standar ICAO agar dapat persetujuan dari negara-negara anggota sehingga FIR Singapura dapat diambil alih.

\section{Penutup}

Kesimpulan dari penelitian ini kepentingan nasional Indonesia dalam mengambil alih FIR Singapura ini ada dua alasan, yaitu alasan utamanya kedaulatan dan keamanan nasional, 
serta alasan lainnya dari segi ekonomi yang strategis. Upaya yang dilakukan oleh Indonesia terkesan lamban dan abai dalam memperhatikan sektor wilayah udara di Kepulauan Riau, Natuna, Batam, dan sekitarnya, padahal wilayah tersebut berbatasan langsung dengan negara lain, terlihat dari ketidak seriusan dari pemerintah dalam berbagai pertemuan ICAO yang tidak membuahkan hasil, dan selama ini wilayah tersebut masih dikuasai oleh Singapura. Padahal, penguasaan wilayah udara sangat menopang visi utama pemerintah saat ini menjadi poros maritim dunia.

Saran peneliti terhadap pemerintah adalah menunjukkan keseriusan dalam mengelola wilayah udara Indonesia secara keseluruhan demi mewujudkan negara yang berdaulat. Adapun upaya yang dapat dilakukan berupa pembentukan batas wilayah udara Indonesia, mempersiapkan Sumber Daya Manusia yang paham dengan industri penerbangan, lalulintas penerbangan, dan paham melakukan diplomasi untuk meningkatkan nilai tawar di Internasional dalam bidang penerbangan. Selain SDM, sangat penting juga teknologi yang mumpuni, kesiapan infrastruktur, serta pembiayaan yang baik dari pemerintah melalui penetapan anggaran yang cukup untuk mewujudkan itu. 


\section{DAFTAR PUSTAKA}

\section{Buku}

Alain de Benoist, 1999, Qu'est-ce que la souveraineté, Terjemahan Julia Kostova, What is Sovereignty? in Éléments, No. 96 (November 1999).

Aleksius Jemadu. 2008. Politik Global dalam Teori dan Praktik. Yogyakarta: Graha Ilmu.

Hans J. Morgenthau, 1949, Natioal Interest and Moral Principle in Foreign policy, The Primacy of the National Interest, American Scholar, XVIII. (Spring, 1949), 208.

Hans J. Morgenthau, 1950, The Mainsprings of American Foreign Policy: The National Interest vs. Moral Abstractions, The American Political Science Review, XLIV (December, 1950), 840-1.

Hans J. Morgenthau,1951, In Defense of the National Interest A. Knopf. New York

P.Anthonius Sitepu. 2011. Studi Hubungan Internasional. Yogyakarta: Graha Ilmu.

Robert Jackson dan Georg Sorensen, 2009. Pengantar Studi Hubungan Internasional. Yogyakarta: Pustaka Pelajar.

\section{Tesis/Skripsi}

Evi Zuarida. 2012. Tinjauan Yuridis Upaya Pengambilalihan Pelayanan Navigasi Penerbangan Pada FIR Singapura Di Atas Wilayah Udara Indonesia Berdasarkan Perjanjian Antara Indonesia Singapura Tahun 1995. Universitas Indonesia, Jakarta.

Muhammad Ridwan Saptian, 2017. Akibat Hukum dari Perjanjian Antara Indonesia dengan Singapura Tentang Flight Information Region (Fir) di Wilayah Udara Kepulauan Natuna. Fakultas Hukum Universitas Pasundan.

\section{Artikel dalam Jurnal}

Baiq Setiani, 2017, Konsep Kedaulatan Negara di Ruang Udara dan Upaya Penegakan Pelanggaran Kedaulatan oleh Pesawat Udara Asing, Jurnal Konstitusi, (14) 3, Hlm. 489-510

David A. Lake, 2003, The New Sovereignty in International Relations International Studies Review, Volume 5, Hlm. 303-323.

Janice E. Thomson, 1995, State Sovereignty in International Relations: Bridging the Gap between Theory and Empirical Research. International Studies Quarterly, Vol. 39, No. 2 (Jun., 1995), Hlm. 213-233

Konigová, L., 2001, Teorie Státní Suverenity a Praxe Intervence. Mezinárodní vztahy 3 (36), Hlm. 41-58.

Morgenthau, H. J, 1948. The Problem of Sovereignty Reconsidered. Columbia Law Review, 48(3), Hlm. 341-365.

Viktor Koščo, 2016, Sovereignty: Analysis of its Current Issues in Certain Countries, Challenges of the Future, volume 1, številka number 1, str, Hlm. 27-41. 


\section{Laporan}

DPR RI, 2015, Laporan Kunjungan Kerja Panitia Kerja Komisi V Dewan Perwakilan Rakyat Republik Indonesia ke Bandara Hang Nadim Batam Provinsi Kepulauan Riau pada 1-2 April 2015, Komisi v DPR RI, Jakarta.

International Civil Aviation Organization, 2001, Annex 11 to the Convention on International Civil Aviation, Thirteenth Edition, July 2001.

Koesnadi Kardi, 2016, Analisa Tentang HUKUM di IndonesiaDalam RangkaPenguatan Sistem Pertahanan Negara, Badan Pembinaan Hukum Nasional Kementerian Hukum dan HAM Republik Indonesia, Jakarta.

Prime Minister's Officer Singapore. (2019, Oktober 8). Remarks by PM Lee Hsien Loong at the Joint Press Conference with Indonesian President Joko Widodo at the SingaporeIndonesia Leaders' Retreat on 8 October 2019. Retrieved from Prime Minister's Officer Singapore: https $/ /$ www.pmo.gov.sg/Newsroom/PM-Lee-Hsien-Loong-atSingapore-Indonesia-Leaders-Retreat-Oct-2019

Seskab RI. (2019, Oktober 8). Joint Press Statement, President of Republic of Indonesia and Prime Minister of Singapore, 8th of October 2019, The Palace, Singapore. Retrieved from Sekertariat Kabinet Republik Indonesia : https://setkab.go.id/joint-pressstatement-president-of-republic-of-indonesia-and-prime-minister-of-singapore-8th-ofoctober-2019-the-palace-singapore/

\section{Website}

CNN Indonesia, 2018, Dua Faktor Ruang Udara Kepri Harus Direbut dari Singapura, CNN Indonesia, https://www.cnnindonesia.com/nasional/20181211175353-20-352864/duafaktor-ruang-udara-kepri-harus-d irebut-dari-singapura, 12 Desember 2018.

Elza Astari Retaduari, 2015, RI Terus Berupaya Rebut Kembali Ruang Udara yang Dikuasai Singapura, Detik.com, https://news.detik.com/berita/d-3010741/ri-terus-berupayarebut-kembali-ruang-udara-yang-d ikuasai-singapura, 04 September 2015.

Kumparan.com, 2018, Singapura Sudah Kuasai Ruang Udara Batam dan Natuna Sejak 1946, Kumparan.com, htps://kumparan.com/@kumparanbisnis/singapura-sudah-kuasairuang-udara-batam-dan-natuna-sejak-1946-1544178031230944523, 7 Desember 2018. 